University of Texas Rio Grande Valley

ScholarWorks @ UTRGV

\title{
Dimensional Latent Structure of ICD-11 Posttraumatic Stress Disorder, Complex PTSD, and Adjustment Disorder: Evidence from Ghana, Kenya, and Nigeria
}

\author{
Ruby Charak \\ The University of Texas Rio Grande Valley, ruby.charak@utrgv.edu \\ Ines Cano-Gonzalez \\ The University of Texas Rio Grande Valley \\ Mark Shevlin \\ Ulster University \\ Menachem Ben-Ezra \\ Ariel University \\ Thanos Karatzias \\ Napier University
}

See next page for additional authors

Follow this and additional works at: https://scholarworks.utrgv.edu/psy_fac

Part of the Psychology Commons

\section{Recommended Citation}

Charak, R., Cano-Gonzalez, I., Shevlin, M., Ben-Ezra, M., Karatzias, T., \& Hyland, P. (2021). Dimensional latent structure of ICD-11 posttraumatic stress disorder, complex PTSD, and adjustment disorder: Evidence from Ghana, Kenya, and Nigeria. Traumatology. Accepted. doi.10.1037/trm0000311

This Article is brought to you for free and open access by the College of Liberal Arts at ScholarWorks @ UTRGV. It has been accepted for inclusion in Psychological Science Faculty Publications and Presentations by an authorized administrator of ScholarWorks @ UTRGV. For more information, please contact justin.white@utrgv.edu, william.flores01@utrgv.edu. 


\section{Authors}

Ruby Charak, Ines Cano-Gonzalez, Mark Shevlin, Menachem Ben-Ezra, Thanos Karatzias, and Philip Hyland 


\title{
Dimensional Latent Structure of ICD-11 Posttraumatic Stress Disorder, Complex
}

\author{
PTSD, and Adjustment Disorder: Evidence from Ghana, Kenya, and Nigeria
}

\author{
Ruby Charak, Ph.D. \\ Ines Cano-Gonzalez, M.A. \\ Department of Psychological Science, The University of Texas Rio Grande Valley, Edinburg, \\ Texas, U.S.A. \\ Mark Shevlin, Ph.D. \\ School of Psychology and Psychology Research Institute, Ulster University, Coleraine, \\ Northern Ireland, U.K. \\ Menachem Ben-Ezra, Ph.D. \\ School of Social Work, Ariel University, Israel \\ Thanos Karatzias, Ph.D. \\ Edinburgh Napier University, School of Health and Social Care, Edinburgh, U.K. \\ Philip Hyland, Ph.D. \\ Department of Psychology, Maynooth University, Ireland
}

Corresponding author: Ruby Charak, Ph.D., Associate Professor, Department of Psychological Science, The University of Texas Rio Grande Valley, Edinburg, Texas 78539, U.S.A. Email: charakruby@ gmail.com Tel: +1-(956)6653733. Fax: +1-(956)6653333.

Funding: The study was funded by an internal research grant awarded to Professor Ben-Ezra from Ariel University [RA1700000037].

APA Citation: Charak, R., Cano-Gonzalez, I., Shevlin, M., Ben-Ezra, M., Karatzias, T., \& Hyland, P. (2021). Dimensional latent structure of ICD-11 posttraumatic stress disorder, complex PTSD, and adjustment disorder: Evidence from Ghana, Kenya, and Nigeria. Traumatology. Accepted. doi.10.1037/trm0000311

(C) 2021, American Psychological Association. This paper is not the copy of record and may not exactly replicate the final, authoritative version of the article. Please do not copy or cite without authors' permission. The final article will be available, upon publication, via its DOI: 10.1037/trm0000311 


\begin{abstract}
With the release of ICD-11 in 2018, there has been a surge in studies examining the nosology of mental disorders, including disorders associated with stress, namely, posttraumatic stress disorder (PTSD), complex PTSD (CPTSD), and adjustment disorder (AjD). Few studies have examined the same in low- and middle-income countries that have disproportionate levels of exposure to trauma and stressors and are under-resourced in mental health services. The present study examined the latent factor structure of a joint model comprising PTSD, CPTSD, and AjD symptoms and their association with stressful and traumatic life events to assess the degree of distinctiveness between these disorders. Participants were 2,524 adults in the age range of $18-71$ years $\left(M / S D_{a g e}=30.44 / 8.67\right)$ from Ghana, $(n=500 ; 50 \%$ female $)$, Kenya ( $n=1,006 ; 49.8 \%$ female), and Nigeria $(n=1,018 ; 50 \%$ female). Findings obtained through confirmatory factor analyses indicated that a dimensional and hierarchical secondorder model comprising correlated latent factors of PTSD, DSO, and AjD provided the best goodness-of-fit indices. Furthermore, it was found that stressors were positively associated with AjD and PTSD, and traumatic life events largely with PTSD. Findings support the ICD11 classification of related-although distinct stress-related disorders in adults from three African nations.
\end{abstract}

Keywords. ICD-11, PTSD, Complex PTSD, Adjustment Disorder, Africa. 


\section{Dimensional Latent Structure of ICD-11 Posttraumatic Stress Disorder, Complex PTSD, and Adjustment Disorder: Evidence from Ghana, Kenya, and Nigeria}

\section{Introduction}

A sequalae of exposure to stressful events can be an array of mental disorders, including anxiety disorders, affective disorders and substance use disorders (Cohen et al., 2019 ; Kilpatrick et al., 2013). Studies indicate that nearly $89.7 \%$ of the general population has experienced at least one stressful life event during their lifetime (Kilpatrick et al., 2013). Notably, posttraumatic stress disorder (PTSD), complex PTSD (CPTSD), and adjustment disorder (AjD) housed in the ICD-11's section on Disorders Associated with Stress (DAS), require exposure to a stressor as a qualifier for diagnosis but differ in the severity or intensity associated with the stressors (stressor vs. traumatic event; Karatzias et al. (2020); Maercker et al. (2013). Per ICD-10 classification, the diagnosis of disorders placed under DAS are relatively higher than the other disorders, with PTSD and AjD being the sixth and eighth most frequently diagnosed disorders by clinicians, respectively (Evan et al., 2013). While these rates suggest the popularity of the diagnoses of PTSD and AjD among clinicians, AjD was ranked lowest in the ease of use or goodness-of-fit in day-to-day clinical practice (Evan et al., 2013; Maercker et al., 2013). Such findings provided an impetus for the improvement of the scientific status of AjD in the new ICD-11.

While there has been a surge in literature focusing on ICD-11's mental health disorders, it is not surprising that the bulk of the research comes from high income countries that mirrors the availability of mental health services and resources for research and the lack thereof in low- and middle income countries (LMICs). As per the World Health Organization's Mental Health Atlas survey (WHO, 2017), globally 37\% of the nations do not have stand-alone mental health laws, and the corresponding proportions rise to $44 \%$ in the continent of Africa (WHO, 2018). These dismal proportions reflect severe deficits in services 
and service providers in the region with more stable regions such as Kenya reportedly having only 80 psychiatrists, 30 clinical psychologists, and less than 500 psychiatric nurses catering to a population of nearly 52 million (Gberie, 2016). In 2016, Ghana reportedly had 3 psychiatric hospitals and around 20 psychiatrists (Gberie, 2016). With a growing population in the midst of scarcity of resources and mental health policies, people in Africa are at an increased risk of mental health problems, including PTSD, CPTSD, and AjD. Hence, there is an urgent need to focus on mental health research in LMICs. The present study aims to contribute to this endeavor by examining the nosology of PTSD, CPTSD and AjD in a joint model to facilitate our understanding of comorbidities in three community samples of adults from three different nations - Ghana, Kenya, and Nigeria—in the continent of Africa.

\subsection{ICD-11 PTSD/CPTSD}

With the release of the World Health Organization's $11^{\text {th }}$ edition of the International Classification of Diseases (ICD-11) in 2018, complex posttraumatic disorder (CPTSD) received formal acceptance as a disorder. Placed in the section on DAS as a sibling disorder of posttraumatic stress disorder (PTSD), CPTSD comprises three symptom-clusters of PTSD and an additional three symptom cluster reflective of disturbances in self-organization (DSO). Specifically, the PTSD symptom clusters are (i) reexperiencing of the trauma in the here and now (RE), (ii) avoidance of traumatic reminders (AV), and (iii) a persistent sense of current threat that is manifested by arousal and hypervigilance (TH). Directly related to a specific traumatic event or series of events, the PTSD symptoms are intended to be fear-based (Hyland et al., 2016).

The conceptualization of CPTSD was originally proposed by Judith Herman to meet the needs of describing symptoms of long-term trauma that included behavioral, emotional, cognitive and interpersonal difficulties, and somatization (Herman, 1992). In ICD-11, CPTSD has the core PTSD symptom clusters, and three symptom clusters, namely, (i) 
affective dysregulation (AD), (ii) negative self-concept (NSC), and (iii) disturbance in relationships (DR). These symptoms are associated with exposure to chronic and multiple forms of traumatic events (e.g., polyvictimization, child sexual abuse, genocide, domestic violence, torture; Brewin et al., 2017). Given its symptom composition, CPTSD is conceptualized as a broader clinical disorder wherein the traumatic event impacts an individuals' emotion regulation, identity, and interpersonal domains (Hyland et al., 2016). Factor analytic studies consistently indicate a distinction between PTSD symptom clusters and DSO symptom clusters, and suggest either a correlated first order six-factor model comprising reexperiencing, sense of threat, avoidance, affective dysregulation, negative selfconcept, and disturbed relationships (e.g., treatment seeking sample from Germany, Bottche et al., 2018; adults refugees residing in the US, Frost et al., 2019; college students from China, Ho et al., 2019; adolescents from Lithuania; Kazlauskas et al., 2020, or a correlated second-order two-factor model wherein the higher order factor of PTSD takes into account the covariance between reexperiencing, sense of threat, and avoidance, and the higher order factor of DSO accounts for the covariances between the factors of affective dysregulation, negative self-concept, and disturbed relationships (e.g., male perpetrators of partner violence from Israel: Gilbar et al., 2018; treatment seeking sample from United Kingdom: $\underline{\text { Hyland et }}$ al., 2017; treatment seeking refugees and asylum seekers in Switzerland: Nickerson et al., 2016 Syrian refugees: Vallieres et al., 2018).

\subsection{Adjustment Disorder}

The diagnosis of adjustment disorder (AjD) made appearance for the first time in the third edition of the Diagnostic and Statistical Manual of Mental Disorder (APA, 1980) and with it followed many controversies over the validity of its nosology. AjD was thus treated as a 'waste-basket' of the psychiatric classification scheme (Casey \& Bailey, 2011) primarily due to its elusive description. Recently, ICD-11 revised the definition of AjD and it is now 
recognized as a stress-response syndrome along with other disorders associated with stress, namely, PTSD, CPTSD, and prolonged grief disorder. A diagnosis of ICD-11AjD requires an experience of at least one identifiable stressor, and maladaptive responses to the stressor(s) in the form of two sets of symptom categories, namely, (i) preoccupation with the stressors or its consequences, and (ii) a failure to adapt. Symptoms of preoccupation with the stressors include excessive worry, recurrent and distressing thoughts about the stressor or constant ruminations about its consequence, and failure to adapt includes symptoms interfering with everyday functioning, such as difficulties in concentration and sleep disturbances. Notably, if the symptoms meet the requirement of another disorder, then that disorder is diagnosed instead of AjD (Maercker et al., 2013).

AjD is caused by a stressful life event and PTSD/CPTSD are precipitated by traumatic life events (Maercker et al., 2013). But there is evidence suggesting that AjD can be predicted by stressful life experiences and prior traumatic event in the same sample (MahatShamir et al., 2017). Comorbidity between the Disorders Associated with Stress, including PTSD/CPTSD and AjD are expected and need to be explored to inform clinical interventions as presence of comorbidity can change treatment plans to avoid a poor prognosis. To our knowledge, only one prior study has attempted to examine the comorbidity between PTSD, CPTSD, and AjD by investigating their dimensional latent structure in a clinical sample from Scotland (Karatzias et al., 2020).

Specifically, in a sample of 331 patients at an outpatient trauma center in Scotland, five models of the latent structure of PTSD, CPTSD, and AjD were investigated for the most optimal model (Karatzias et al., 2020). Model 1 was the 'Stress response' model wherein all items of the three disorders loaded on a single latent factor. Assuming a unidimensional structure of each disorder, Model 2 specified the PTSD, CPTSD, and AjD items on three first-order latent factors, namely, 'PTSD,' 'DSO', and 'Adjustment disorder.' Model 3 
assumed the multidimensional nature of each disorder and comprised eight correlated firstorder latent variables with no hierarchical organization. Model 4 tested the variation and covariation among the eight first-order latent variables as explained by a single second-order latent factor 'Stress response.' A close representation of the ICD-11, Model 5 had the three disorders as multidimensional and hierarchical and optimally fitted the data in comparison to other models. Specifically, the AjD items were specified to measure two latent factors, 'preoccupation' and 'failure to adapt', and the variation and covariation between these firstorder latent factors were specified to be explained by the single second-order latent factor of 'Adjustment disorder.' It also specified two correlated second-order factors-PTSD and DSO - to explain the covariation among the six first-order factors, namely, reexperiencing, avoidance, and sense of threat loaded on the PTSD latent factor, and negative self-concept and affect regulation loaded on the DSO latent factor. All three second-order factors of PTSD, DSO, and AjD were also correlated to explain the covariance between the eight firstorder factors. Additionally, the study also examined the predictive utility of different types of stressors and traumatic events to enable differential diagnosis for these disorders. The present study will examine these joint structures of PTSD, DSO, and AjD in three community samples of adults from Ghana, Kenya, and Nigeria in Africa. We also investigate the predictive utility of lifetime stressors and traumatic events to facilitate differential diagnosis between the three conditions. This would highlight the optimal dimensional structure and the degree of distinctiveness of these disorders in samples from Africa.

\subsection{The Present Study}

The current study aimed to examine a joint latent factor structure of PTSD, DSO, and $\mathrm{AjD}$ in order to yield the distinguishability between three disorders in ICD-11, namely, PTSD, CPTSD, and AjD in three large community sample of adults from Kenya, Nigeria and Ghana in Africa. To the best of our knowledge, this is the first study examining the joint 
factor structure in community samples from a non-western country. A series of five structural models suggested by Karatzias et al. (2020) will be tested across the three samples. First, we hypothesize that the joint latent factor model that bears close semblance to the ICD-11 representation of the three disorders wherein each measure (of the disorder) is multidimensional and hierarchical (Model 5, Karatzias et al., 2020) will be the most parsimonious and with the best goodness-of-fit indices. Second, we hypothesize that exposure to lifetime stressors would predict the latent factor of AjD and PTSD (MahatShamir et al., 2017); however, only exposure to traumatic events would predict the latent factor structure of PTSD and DSO (Karatzias et al., 2020; Mahat-Shamir et al., 2017).

\section{Method}

\subsection{Participants}

The study sample comprised a total of 2,524 participants from Ghana $(n=500,19.8$ $\%)$, Kenya $(n=1,006,39.9 \%)$, and Nigeria $(n=1,018 ; 40.3 \%)$. The gender (binary gender) of the participants was equally distributed across the three samples (Ghana, $n=250,50 \%$ female; Kenya, $n=505,50.2 \%$, males, $n=501,49.8 \%$ females; Nigeria, $n=518,50.9 \%$ males, $n=50049.1 \%$ females. Participants from Ghana were between 18-68 years old $(M=$ $28.96, S D=7.93)$, from Kenya between $18-71$ years old $(M=30.14, S D=8.72)$, and from Nigeria between $17-68$ years old $(M=32.23, S D=9.36)$. Other demographic details are provided in Table 1.

\subsection{Measures}

2.2.1. ICD-11 PTSD and CPTSD. The International Trauma-Questionnaire (ITQ: (Cloitre et al., 2018) is a self-report measure of ICD-11 PTSD and CPTSD. The ITQ is composed of 18 items distributed in two sections, (i) PTSD (9 items) and (ii) Disturbances of self-organization (DSO, 9 items). The first section is composed of 6 items that measure PTSD symptoms (re-experiencing, RE1 and RE2; avoidance, AV1 and AV2; and sense of threat, 
TH1 and TH2), and three items measuring functional impairment association with PTSD. Similarly, the second section was composed of 6 items measuring DSO (affective dysregulation, AD1 and AD2; negative self-concept, NSC1 and NSC2; disturbances in relationships, DR1 and DR2) and three items measuring functional impairment associated with DSO. Each item is measured on a five-point Likert scale ranging from $0=$ 'Not at all' to $4=$ 'Extremely'. For a diagnosis of PTSD, endorsement of at least one symptom in each cluster (RE, AV, and TH) with a score of 2 or greater (from $2=$ Moderately to $4=$ Extremely) and show the same score $(\geq 2)$ on the three functional impairment items. For a diagnoses of CPTSD, participants must have a PTSD diagnosis and additionally endorse at least one symptom in each DSO cluster (AD, NSC, and DR) with a score of 2 or greater (i.e., from $2=$ Moderately to $4=$ Extremely) and show same score $(\geq 2)$ on the three functional impairment items, indicative of impairment social life, work-life, and other important obligations.

For the propose of the present study, only the items regarding the core symptoms were used (RE, AV, TH, AD, NSC, and DR). The preliminary versions of ITQ shows good construct validity (Hyland et al., 2017; Karatzias et al., 2016), that is, significant positive correlations of PTSD with other measures of PTSD of DSM-5 indicative of a good convergent validity (Karatzias et al., 2016). Discriminant validity was conducted comparing the PTSD and DSO scores with other mental health outcomes (Hyland et al., 2017). The ITQ has been validated and used on several populations (e.g., United Kindom: Cloitre et al., 2018); Israel: Gilbar et al., 2018; Germany: Karatzias et al., 2017). The Cronbach's alpha for the present study were acceptable (PTSD core symptoms: Ghana sample, $\alpha=.67$ to .84 ; Kenya sample, $\alpha=.68$ to .80 ; Nigeria sample, $\alpha=.65$ to .79 ; DSO core symptoms range from: Ghana sample, $\alpha=.64$ to .91 ; Kenya sample, $\alpha=.66$ to .91 ; Nigeria sample, $\alpha=.72$ to $.90)$. The low reliability may be due to the small number of variables per core symptoms (two items), which is likely to underestimate the true reliability (Eisinga et al., 2013). 


\subsubsection{Adjustment disorder. Adjustment Disorder New Module (ADNM-20; Einsle}

et al., 2010) is a self-report scale that measures ICD-11 Adjustment disorder. The ADNM-20 consists of two parts, (i) a list of common stressors and (ii) a list of symptoms of Adjustment Disorder. The first part is composed of 16 stressors (e.g., family conflicts, serious accidents, and unemployment) measured as (0) absence or (1) presence of the stressors. The stressor list comprises seven types of acute events (e.g., divorce, moving) and nine types of chronic stressors (e.g., conflict with neighbors, serious illness). The total score is calculated by adding the 16 items to represent cumulative stress (ranging from 0 to 16). Due to the large number of items, all participants with total scores of 7 or greater were recoded as 6 in the present study. The second part comprises 20 items (19 items AjD symptomatology and one functional impairment) answered in a 4-point Likert scale indicating how frequently each symptom was experienced $(1=$ 'never' to $4=$ 'often' $)$.

For the purpose of the present study, the eight items that reflect the two clusters of the core symptomatology were used (preoccupations with the stressor: PR1-PR4, and failure to adapt: FA1-FA4). For a diagnosis of AjD, participants must identify at least one stressful event and score $\geq 3$ in one symptom and a score of at least $\geq 2$ in two items across both clusters and a rating $\geq 3$ on the functional impairment criterion. The ADMN-20 was first developed and tested in two samples from outpatient clinics (Einsle et al., 2010). The ADMN-20 showed good internal reliability $(\alpha=.80-.90)$ (Lorenz et al., 2016) and re-test reliability $\left(r_{t t}=.61\right.$ to .84$)$ (Einsle et al., 2010). Similarly, the present measure showed good construct validity (Einsle et al., 2010) and diagnostic validity (Lorenz et al., 2016). The factor structure of ADMN-20 has not yet been tested in any country in the continent of Africa. The internal consistency of the core items of ADNM-20 was good (Ghana sample: PR $\alpha=.88$ and FA $\alpha=.82$; Kenya sample: PR $\alpha=.85$ and FA $\alpha=.84$; Nigeria: PR $\alpha=.83$ and FA $\alpha=.95$ ). 


\subsubsection{Traumatic and Stressful Life Events. The Life Events Checklist (LEC: Gray}

et al., 2004) is a 17-item self-report measure that screen potentially traumatic events in the participant's lifetime. The LEC assesses lifetime exposure to 16 traumatic events (e.g., natural disaster, physical assault, life-threatening illness/injury) and one last item that allows the participants to indicate any other traumatic experience that is not listed ("Any other very stressful event/experience"). Items are measured in a five-point Likert scale which indicates the levels of exposure $(1=$ 'Happened to me', 2 = 'Witnessed it happening to somebody else', 3 = 'Learned about it happening to someone close to me', $4=$ 'Part of my job', 5 = 'Not sure it applies', 6 = 'Doesn't apply to my experience'). In the present study, items were recoded as (i) presence, those that indicated 1 ("Happened to me") and all other levels of exposure as (0) absence, except for items 14 (sudden violent death, for example, homicide, suicide) and 15 (sudden accidental death) that response 2 (witnessed it happening to somebody else) was also recoded as (1) presence. The total score was calculated, adding all items, except for item 17, ranging from 0 to 16 , with a higher score indicative of exposure to more types of traumatic events.

\subsection{Procedure}

The selection of the countries to incorporate in the study was made based on their high internet presence and English proficiency (Kiprop, 2018; Silver \& Johnson, 2018). The countries selected were Nigeria, Kenya, and Ghana. Ethical approval to carry out the study via an online survey were requested and approved by the Ariel University, Israel (author MBE's university). Participants signed an electronic informed consent before answering the questionnaire. Eligibility criteria after country selection were (i) citizenship of one of the three countries mentioned above; (ii) being 18 years old or above.

\subsection{Statistical Analysis}


The data analytical approach for this study followed two stages. First, descriptive statistics to test the sample's characteristics and bivariate correlations to test the association between the study variables were analyzed in IBM SPSS version 26. Second, factor analytic analyses were conducted in Mplus version 8.4. Figure 1 shows the five alternative models tested as representing the AjD, PTSD, and DSO symptoms. Models 1-5 were the models tested by Karatzias et al. (2020) as described previously (see Figure 1). is a one-factor model where all symptoms load on the single latent variable (stress response). Model 6 tests the predictive ability of LEC traumatic events and ADMN-16 stressors predictive on the three second-order factors mentioned above.

Each model was specified and estimated using robust maximum likelihood (MLR; Yuan \& Bentler, 2000), and weighted least squares means and variance adjusted (WLSMV; Muthén, 1997). The WLSMV (versus the MLR) estimation on the latent continuous response variable's polychoric correlation matrix is more appropriate when items have fewer than 5 response categories (Rhemtulla et al., 2012). Goodness-of-fit for each model was assessed with the indices of chi-square, the comparative fit index (CFI), and the Tucker-Lewis Index (TLI). Acceptable model fit was considered when the chi-square was non-significant, and CFI and TLI were greater than .90. Moreover, the Root Mean Square Error of Approximation (RMSEA) with a value less than 0.05 indicating close fit and values up to .08 , indicating reasonable errors of approximation ( $\mathrm{Hu} \&$ Bentler, 1999). Additionally, to compare the models, BIC was generated using MLR estimation. Once that the best-fitting model of ICD11 CPTSD was identified, Model 6 was created by adding the predictors on the identified latent variables. Last, composite reliability for the preferred model was calculated. Composite reliability is an alternative to Cronbach's alpha that estimates the internal consistency of a group of items without the strict assumptions of tau-equivalence (Raykov, 1997).

\section{Results}




\subsection{Descriptive statistics}

Tables 1, 2 and 3 contains bivariate correlations between the scores of the stressor's measures and the ADNM and ITQ subscales. Participants indicated the number of traumatic events and stressors experienced in their lifetime. Scores on the summed LEC ranged from 0 to 15 for the three countries (Ghana, $M=3.25, S D=2.93$; Kenya, $M=3.82, S D=3.09$; Nigeria, $M=3.79, S D=3.02)$. The prevalence of the most common stressors and traumatic events are reported in Table 1. The endorsement of $\mathrm{AjD}$ without excluding those that met criteria for PTSD and CPTSD was 23.4\% $(n=117)$ for Ghana, $27.8 \%(n=280)$ for Kenya and $17.7 \%$. $(n=180)$ for Nigeria. Around a third of the participants met the criteria for PTSD (Ghana, $n=153,30.6 \%$; Kenya, $n=372,37.9 \%$; Nigeria $n=346,34.0 \%$.) and in a lesser extend met the criteria for complex PTSD (Ghana, $n=65,13.0 \%$; Kenya, $n=197,19.6 \%$; Nigeria, $n=139,13.7 \%$ ).

\subsection{The latent structure of AjD, PTSD, and CPTSD}

The factor analytic analyses were carried out across the three different countries. Derived fit indices from MLR and WLSMV (see Tables 3) indicated that the multidimensional models with 8 first-order factors (Models 3, 4 and 5) fitted the data better than the 1 and 3 factor models (Models 1 and 2) for the three countries. The best fitting model means a balanced model fit and simplicity. As reported in Tables 4, 5, and 6, the RMSEA, CFI, TLI, and SRMR overall indicated acceptable fit for Models 3 and 5. However, the lower BIC in Model 5 indicated a better fit.

As the figures 2, 3 and 4 indicate all the loadings are positive and statistically significant $(p<.05)$. The correlations among the second order latent variables were all positive and statistically significant for the Ghana sample (DSO-PTSD, $r=.581$; AjD-PTSD, $r=.573$; AjD-DSO $r=.686$ ), Kenya sample (DSO-PTSD, $r=.607$; AjD-PTSD, $r=.583$; AjD-DSO $r=.673$ ), and Nigeria sample (DSO-PTSD, $r=.651$; AjD-PTSD, $r=.638$; AjD- 
DSO $r=.770$ ). Based on estimates derived from the CFA analysis composite reliability indicated that the eight first-order subscales demonstrated good reliability across the three countries (ranging from, $\mathrm{RE}=.749$ to $.782 \mathrm{AV}=.796$ to $.837, \mathrm{TH}=.657$ to $.690, \mathrm{AD}=.671$ to $.731, \mathrm{NSC}=.904$ to $.916, \mathrm{DR}=.806$ to $.844, \mathrm{PR}=.855$ to .879 , and $\mathrm{FA}=.821$ to .841 ). Similarly, excellent reliability was found for the four items of PTSD (.893 to .904), the four of DSO (.930 to .931), and eight of AjD (.917 to .920),

Once the best fit model was indicated (model 5), predictors were added into the analysis creating model 6 (which contains eight first-order, three second order with predictors; see figure 2, 3, and 4). In these models, the ADNM-20 stressors and the LEC were added to the model and were specified to be correlated; the three second-order factors were regressed on these three trauma variables. Findings indicated that acute psychosocial and persistent stressors were predictors of $\mathrm{AjD}(b=.14$ to .26$)$ and PTSD $(b=.20$ to .43$)$ across the three samples. Similarly, potentially traumatic events were predictors of PTSD $(b=.31$ to .44) for the three samples and of DSO for the Ghana sample only $(b=.18)$.

\section{Discussion}

\subsection{Main findings}

The present study aimed to examine the joint latent structure of three disorders in the ICD-11s DAS, namely, PTSD, CPTSD, and AjD, and also investigated the predictive value of lifetime stressors and traumatic events on PTSD, DSO, and AjD. Our first hypothesis was accepted as we found that the multidimensional and hierarchical joint latent factor model with 8 first-order factors - reexperiencing, avoidance, sense of threat, negative self-concept, affect regulation, preoccupations with the stressor, and failure to adapt — and three secondorder factors-PTSD, DSO and AjD—had the overall best goodness-of-fit indices among the five models examined. Our second hypothesis was partially supported as exposure to lifetime stressors predicted PTSD and AjD but not DSO across the three samples, and exposure to 
lifetime traumatic events predicted PTSD only in the samples from Kenya and Nigeria, but it predicted PTSD and DSO in the Ghanaian sample. This study is the first to examine and find evidence for a joint latent factor model of PTSD, DSO, and AjD in adults community samples from Africa and the second study from across the globe after Karatzias et al. (2020). Findings are discussed in detail below.

Although not a hypothesis, it is important to highlight that in contrast to rates of AjD found in population based non-clinical sample from Ireland (i.e., 15.6\%; Shevlin et al., 2020) and Lithuania (16.5\%; Zelviene et al., 2020) without applying exclusion rules, the rates were higher (17.7\% to $27.8 \%$ ) in the present community sample of adults from the three African countries. In fact, the rates found in the study-samples were comparable to a high-risk sample from other western/developed nations (i.e., $27.3 \%$ in a sample from Switzerland; Perkonigg et al., 2018). Similarly, rates of PTSD (30.6\% to 37.9\%) and CPTSD (13\% to $19.6 \%$ ) found in present samples were higher than those found in non-clinical samples from developed nations (e.g., Israel: 9\% PTSD vs. 2.6\% CPTSD; Ben-Ezra et al., 2018). Furthermore, the average exposure to stressors was nearly two times higher in the present samples compared to a clinical sample from Scotland $(M=4.79$; Karatzias et al., 2020) and the average exposure to traumatic events was similar $(M=3.99)$. These higher and comparable rates of stressors and trauma exposure in population-based samples from Africa (vs. clinical samples from the west) reflects their increased risk of exposure to multiple stressful experiences and traumatic events that can have an accumulating and detrimental effect on one's wellbeing (e.g., $\underline{\text { Charak }}$ et al., 2017; Cohen et al., 2019). These higher rates of stressors, traumatic events, and higher rates of AjD, PTSD, and CPTSD are a reflection of the deficits in mental health services and legislative mental health policies in many regions of Africa (Sankoh et al., 2018) as also highlighted by the WHOs Mental Health Atlas Report (WHO, 2017). 
The present findings from the joint model support the distinctiveness of PTSD, CPTSD, and AjD as separate disorders as per the classifications in ICD-11. These findings conceptually replicate the findings of Karatzias et al. (2020) as they too found that the model with eight first-order factors - reexperiencing, avoidance, sense of threat, negative selfconcept, affect regulation, preoccupations with the stressor, and failure to adapt — and three second-order factors-PTSD, DSO and AjD fit the data best, albeit in a clinical sample. There was moderate factor covariances between PTSD, DSO and AjD reflective of some amount of comorbidity but also independence between the latent factors. The factor covariance between AjD and DSO was the highest across all the three samples that was also found in the trauma exposed clinical sample from Scotland (Karatzias et al., 2020). These high covariances in the joint latent model can be viewed from the dimensional model of psychopathology — the hierarchical taxonomy of psychopathology — that proposes six spectra/dimensions of psychopathology including internalization and externalization (Forbes et al., 2016; Kotov et al., 2017). The DAS disorders of PTSD, CPTSD, and AjD would all be subsumed under the internalizing dimension that is characterized by negative affect, thus accounting for the comorbidity between the three disorders.

Furthermore, our findings that exposure to stressors predicted AjD and PTSD and that traumatic events largely predicted PTSD and DSO are in line with the criteria set in ICD-11 (WHO, 2018) and with a meta analytic study of 22 samples that exposure to both stressors and/or traumatic events is associated with posttraumatic stress symptoms although the magnitude of association is higher between traumatic events and posttraumatic stress symptoms (Larsen \& Pacella, 2016). Our findings are in contrast to Mahat-Shamir et al. (2017) wherein they found stressors to be predictive of AjD only and traumatic events to be related with both PTSD and AjD, and with Karatzias et al. (2020) findings that stressors and traumatic event lead to AjD, PTSD, and DSO. Although the average exposure to traumatic 
events was comparable between our community samples from Africa and the clinical sample from Scotland, it is noteworthy that rates of PTSD/CPTSD and AjD were higher in the clinical sample from Scotland. While these higher rates of diagnoses in a clinical sample compared to the rates in the present community-based samples are not surprising, they suggest that a number of additional characteristics of risk-multiple exposure, chronicity, interpersonal vs. non-interpersonal nature of the stressor-and protective factors (e.g., social support; Cohen et al., 2019; Hirai et al., 2020) can influence the associations between exposure to stressor vs. traumatic event, AjD, PTSD and CPTSD. Prior studies indicate that these characteristics are associated with an increased severity in psychopathological reactions (Cohen et al., 2019; Forbes et al., 2016). Consideration of these factors may have also explained our non-significant findings of lifetime trauma events as a predictor of DSO in Nigerian and Kenyan samples. Future studies should thus take into consideration the various characteristics of a stressor and traumatic events to better understand the conditions in which the magnitude of certain stressors causes harm and threat leading to posttraumatic stress reactions.

\subsection{Limitations}

The present study findings should be interpreted with the following limitations in mind. First, the study was based on a convenience sample of adults from Kenya, Ghana and Nigeria and cannot be generalized to the population at large. Second, this study was based on self-reported measures and was a cross-sectional design. The factor analytic joint model may reflect the properties of the self-report measures rather than the diagnostic classifications. Although clinician administered diagnostic interview are yet to be empirically tested for ICD$11 \mathrm{AjD}$, there is one study that has empirically tested the use of International Trauma Interview, a diagnostic interview for ICD-11 PTSD/CPTSD (Bondjers et al., 2019). Third, data were collected online in English language and from those with internet access. This 
limited its accessibility to those with a higher education and economic status, and English proficiency. Notably, prior studies suggest that online forums provide anonymity to participants that may increase comfort and willingness to disclose sensitive information (e.g., regarding traumatic events) about themselves (Tourangeau, 1996).

\subsection{Implications and conclusions}

Nonetheless, the present findings have important implications and avenues for future research. Our findings that exposure to multiple stressors, traumatic events, rates of PTSD/CPTSD and AjD were higher in the three samples from Africa (vs. samples from the west) calls for more preventative interventions and strengthening the availability and capacity of mental health services and professionals in the region (Tol et al., 2014; WHO, 2018). For example, prior studies based on samples from under-resourced regions suggest a balanced approach with capacity building in terms of specialty care and non-specialist health care workers in community and primary care settings (Thornicroft \& Tansella, 2013; Tol et al., 2014). The joint model suggests that there is comorbidity between AjD, PTSD, and CPTSD that stands in contrast to the classifications in ICD-11. Findings have implications for clinical interventions as a recent meta-analytic study examining the effectiveness of psychological interventions for PTSD/CPTSD found preliminary evidence that although trauma-focused interventions are effective in symptom reduction associated with traumatic memories, some non-trauma focused therapies, such as mindfulness and interpersonal therapy may also reduce symptoms of avoidance behavior in interpersonal relationships, disturbances in relationships, and developing a positive self-concept (Cloitre et al., 2012; Karatzias et al., 2019). Notably, the treatment consideration for borderline personality disorder that is often comorbid with PTSD include the focus is on alleviating self-harm behavior, fear of abandonment, alleviating chaotic relationships and establishing a stable sense of self through interventions such as Dialectical Behavioral therapy (Linehan, 1993). For AjD, CBT appears to bear promising 
results (Maercker et al., 2015) although more cost-effective solutions-low intensity self-help interventions, internet-delivered interventions - will have to be developed for health care in under-resourced regions of the world (Eimontas et al., 2018; Maercker et al., 2015).

To conclude, our findings support the multidimensional and hierarchical model of ICD-11's DAS by examining a joint model of PTSD, CPTSD, and AjD in a culturally diverse sample from Kenya, Ghana, and Nigeria. Additionally, exposure to stressors and traumatic events had a differential effect on AjD and PTSD, with exposure to stressors being predictive of AjD and PTSD, and traumatic events largely predictive of PTSD. 


\section{References}

APA. (1980). Diagnostic and statistical manual of mental disorders (3th ed.). American Psychiatric Association.

Ben-Ezra, M., Karatzias, T., Hyland, P., Brewin, C. R., Cloitre, M., Bisson, J. I., Roberts, N. P., Lueger-Schuster, B., \& Shevlin, M. (2018). Posttraumatic stress disorder (PTSD) and complex PTSD (CPTSD) as per ICD-11 proposals: A population study in Israel. Depression and Anxiety, 35(3), 264-274. https://doi.org/10.1002/da.22723

Bondjers, K., Hyland, P., Roberts, N. P., Bisson, J. I., Willebrand, M., \& Arnberg, F. K. (2019). Validation of a clinician-administered diagnostic measure of ICD-11 PTSD and complex PTSD: the International Trauma Interview in a Swedish sample. European Journal of Psychotraumatology, 10(1), 1665617.

Bottche, M., Ehring, T., Kruger-Gottschalk, A., Rau, H., Schafer, I., Schellong, J., Dyer, A., \& Knaevelsrud, C. (2018). Testing the ICD-11 proposal for complex PTSD in traumaexposed adults: factor structure and symptom profiles. European Journal of Psychotraumatology, 9(1), 1512264. https://doi.org/10.1080/20008198.2018.1512264

Brewin, C. R., Cloitre, M., Hyland, P., Shevlin, M., Maercker, A., Bryant, R. A., Humayun, A., Jones, L. M., Kagee, A., Rousseau, C., Somasundaram, D., Suzuki, Y., Wessely, S., van Ommeren, M., \& Reed, G. M. (2017). A review of current evidence regarding the ICD-11 proposals for diagnosing PTSD and complex PTSD. Clinical Psychology Review, 58, 1-15. https://doi.org/10.1016/j.cpr.2017.09.001

Casey, P., \& Bailey, S. (2011). Adjustment disorders: the state of the art. World Psychiatry, 10(1), 11-18. https://doi.org/ https://doi.org/10.1002/j.2051-5545.2011.tb00003.x

Charak, R., de Jong, J., Berckmoes, L. H., Ndayisaba, H., \& Reis, R. (2017). Assessing the factor structure of the Childhood Trauma Questionnaire, and cumulative effect of 
abuse and neglect on mental health among adolescents in conflict-affected Burundi. Child Abuse and Neglect, 72, 383-392. https://doi.org/10.1016/j.chiabu.2017.09.009

Cloitre, M., Courtois, C. A., Ford, J. D., Green, B. L., Alexander, P., Briere, J., Herman, J. L., Lanius, R., Stolbach, B. C., Spinazzola, J., Van der Kolk, B.A., \& Van der Hart, O. (2012). The ISTSS expert consensus treatment guideline for complex PTSD in adults. Retrieved from http://www.istss.org

Cloitre, M., Shevlin, M., Brewin, C. R., Bisson, J. I., Roberts, N. P., Maercker, A., Karatzias, T., \& Hyland, P. (2018). The International Trauma Questionnaire: development of a self-report measure of ICD-11 PTSD and complex PTSD. Acta Psychiatrica Scandinavica, 138(6), 536-546. https://doi.org/10.1111/acps.12956

Cohen, S., Murphy, M. L. M., \& Prather, A. A. (2019). Ten surprising facts about stressful life events and disease risk. Annual Review of Psychology, 70, 577-597. https://doi.org/10.1146/annurev-psych-010418-102857

Eimontas, J., Rimsaite, Z., Gegieckaite, G., Zelviene, P., \& Kazlauskas, E. (2018). Internetbased self-help intervention for ICD-11 Adjustment Disorder: Preliminary findings. The Psychiatric Quarterly, 89(2), 451-460. https://doi.org/10.1007/s11126-017-9547$\underline{2}$

Einsle, F., Kollner, V., Dannemann, S., \& Maercker, A. (2010). Development and validation of a self-report for the assessment of adjustment disorders. Psychology, Health \& Medicine, 15(5), 584-595. https://doi.org/10.1080/13548506.2010.487107

Eisinga, R., Grotenhuis, M., \& Pelzer, B. (2013). The reliability of a two-item scale: Pearson, Cronbach, or Spearman-Brown? International Journal of Public Health, 58(4), 637642. https://doi.org/10.1007/s00038-012-0416-3

Evans, S. C., Reed, G. M., Roberts, M. C., Esparza, P., Watts, A. D., Correia, J. M., Ritchie, P., Maj, M., \& Saxena, S. (2013). Psychologists perpectives on the diagnostic 
classification of mental disorders: results from the WHO-IUPsyP global sruvey. International Journal of Psychology, 48(3), 177-193.

doi.org/10.1080/00207594.2013.804189

Forbes, M. K., Tackett, J. L., Markon, K. E., \& Krueger, R. F. (2016). Beyond comorbidity: Toward a dimensional and hierarchical approach to understanding psychopathology across the life span. The Journal of Clinical Psychiatry, 28(2), 971-986. https://doi.org/10.1017/S0954579416000651

Frost, C. J., Morgan, N. J., Allkhenfr, H., Dearden, S., Ess, R., Albalawi, W. F., Berri, A., Benson, L. S., \& Gren, L. H. (2019). Determining physical and mental health conditions present in older adult refugees: A mini-review. Gerontology, 65(3), 209215. https://doi.org/10.1159/000491695

Gberie, L. (2016). Mental illness: invisible but devastating. Africa Renewal. Retrieved from https://www.un.org/africarenewal/magazine/december-2016-march-2017/mentalillness-invisible-devastating

Gilbar, O., Hyland, P., Cloitre, M., \& Dekel, R. (2018). ICD-11 complex PTSD among Israeli male perpetrators of intimate partner violence: Construct validity and risk factors. Journal of Anxiety Disorders, 54, 49-56. https://doi.org/10.1016/j.janxdis.2018.01.004

Glaesmer, H., Romppel, M., Brahler, E., Hinz, A., \& Maercker, A. (2015). Adjustment disorder as proposed for ICD-11: Dimensionality and symptom differentiation. Psychiatry Research, 229(3), 940-948. https://doi.org/10.1016/j.psychres.2015.07.010

Gray, M. J., Litz, B. T., Hsu, J. L., \& Lombardo, T. W. (2004). Psychometric properties of the life events checklist. Assessment, 11(4), 330-341. https://doi.org/10.1177/1073191104269954 
Herman, J. L. (1992). Complex PTSD: A syndrome in survivors of prolonged and repeated trauma. Journal of Traumatic Stress, 5(3), 377-391. https://doi.org/10.1002/jts.2490050305

Hirai, M., Charak, R., Seligman, L. D., Hovey, J. D., Ruiz, J. M., \& Smith, T. W. (2020). An association between perceived social support and posttraumatic stress symptom severity among women with lifetime sexual victimization: the serial mediating role of resilience and coping. Violence Against Women, 26(15-16), 1966-1986. https://doi.org/10.1177/1077801219892645

Ho, G. W. K., Karatzias, T., Cloitre, M., Chan, A. C. Y., Bressington, D., Chien, W. T., Hyland, P., \& Shevlin, M. (2019). Translation and validation of the Chinese ICD-11 International Trauma Questionnaire (ITQ) for the ssessment of Posttraumatic Stress Disorder (PTSD) and Complex PTSD (CPTSD). European Journal of Psychotraumatology, 10(1), 1608718. https://doi.org/10.1080/20008198.2019.1608718

Hu, L. T., \& Bentler, P. M. (1999). Cutoff criteria for fit indexes in covariance structure analysis: Conventional criteria versus new alternatives. Structural Equation Modeling: A Multidisciplinary Journal, 6(1), 1-55.

\section{https://doi.org/10.1080/10705519909540118}

Hyland, P., Shevlin, M., Brewin, C. R., Cloitre, M., Downes, A. J., Jumbe, S., Karatzias, T., Bisson, J. I., \& Roberts, N. P. (2017). Validation of post-traumatic stress disorder (PTSD) and complex PTSD using the International Trauma Questionnaire. Acta Psychiatric Scandinavica, 136(3), 313-322. https://doi.org/10.1111/acps.12771

Hyland, P., Shevlin, M., Elklit, A., Murphy, J., Vallieres, F., Garvert, D. W., \& Cloitre, M. (2016). An assessment of the construct validity of the ICD-11 proposal for complex 
posttraumatic stress disorder. Psychological Trauma, 9(1), 1-9. https://doi.org/10.1037/tra0000114

Karatzias, T., Cloitre, M., Maercker, A., Kazlauskas, E., Shevlin, M., Hyland, P., Bisson, J. I., Roberts, N. P., \& Brewin, C. R. (2017). PTSD and Complex PTSD: ICD-11 updates on concept and measurement in the UK, USA, Germany and Lithuania. European Journal of Psychotraumatoly, 8(7), 1418103. https://doi.org/10.1080/20008198.2017.1418103

Karatzias, T., Murphy, P., Cloitre, M., Bisson, J., Roberts, N., Shevlin, M., Hyland, P., Maercker, A., Ben-Ezra, M., Coventry, P., Mason-Roberts, S., Bradley, A., \& Hutton, P. (2019). Psychological interventions for ICD-11 complex PTSD symptoms: systematic review and meta-analysis. Psychological Medicine, 49(11), 1761-1775. https://doi.org/10.1017/S0033291719000436

Karatzias, T., Shevlin, M., Fyvie, C., Hyland, P., Efthymiadou, E., Wilson, D., Roberts, N., Bisson, J. I., Brewin, C. R., \& Cloitre, M. (2016). An initial psychometric assessment of an ICD-11 based measure of PTSD and complex PTSD (ICD-TQ): Evidence of construct validity. Journal of Anxiety Disorders, 44, 73-79. https://doi.org/10.1016/j.janxdis.2016.10.009

Karatzias, T., Shevlin, M., Hyland, P., Fyvie, C., Grandison, G., \& Ben-Ezra, M. (2020). ICD-11 posttraumatic stress disorder, complex PTSD and adjustment disorder: the importance of stressors and traumatic life events. Anxiety Stress Coping, 1-12. https://doi.org/10.1080/10615806.2020.1803006

Kazlauskas, E., Zelviene, P., Daniunaite, I., Hyland, P., Kvedaraite, M., Shevlin, M., \& Cloitre, M. (2020). The structure of ICD-11 PTSD and Complex PTSD in adolescents 
exposed to potentially traumatic experiences. Journal of Affective Disorders, 265, 169-174. https://doi.org/10.1016/j.jad.2020.01.061

Kilpatrick, D. G., Resnick, H. S., Milanak, M. E., Miller, M. W., Keyes, K. M., \& Friedman, M. J. (2013). National estimates of exposure to traumatic events and PTSD prevalence using DSM-IV and DSM-5 criteria. Journal of Trauma and Stress, 26(5), 537-547. https://doi.org/10.1002/jts.21848

Kiprop, V. (December 12, 2018). English-speaking countries in Africa. https://www.worldatlas.com/articles/english-speaking-countries-in-africa.html

Kotov, R., Krueger, R. F., Watson, D., Achenbach, T. M., Althoff, R. R., Bagby, R. M., ...\& Zimmerman, M. (2017). The Hierarchical Taxonomy of Psychopathology (HiTOP): A dimensional alternative to traditional nosologies. Journal of Abnormal Psychology, 126(4), 454-477. https://doi.org/10.1037/abn0000258

Larsen, S. E., \& Pacella, M. L. (2016). Comparing the effect of DSM-congruent traumas vs. DSM-incongruent stressors on PTSD symptoms: A meta-analytic review. Journal of Anxiety Disorder, 38, 37-46. https://doi.org/10.1016/j.janxdis.2016.01.001

Linehan, M. (1993). Cognitive-behavioral treatment of borderline personality disorder. The Guildford Press.

Lorenz, L., Bachem, R. C., \& Maercker, A. (2016). The Adjustment Disorder--New Module 20 as a Screening Instrument: Cluster Analysis and Cut-off Values. International Journal of Occupational and Environmental Medicine, 7(4), 215-220. https://doi.org/10.15171/ijoem.2016.775

Maercker, A., Bachem, R. C., Lorenz, L., Moser, C. T., \& Berger, T. (2015). Adjustment disorders are uniquely suited for ehealth interventions: Concept and case study. JMIR Mental Health, 2(2), e15. https://doi.org/10.2196/mental.4157 
Maercker, A., Brewin, C. R., Bryant, R. A., Cloitre, M., Reed, G. M., van Ommeren, M., Humanyun, A., Jones, L. M., Kagee, A., Llosa, A. E., Rousseau, C., Somasundaram, D. J., Souza, R., Suzuki, Y., Weissbecker, I., Wessely, S. C., First, M. B., \& Saxena, S. (2013). Proposals for mental disorders specifically associated with stress in the International Classification of Diseases-11. The Lancet, 381(9878), 1683-1685. https://doi.org/10.1016/s0140-6736(12)62191-6

Mahat-Shamir, M., Ring, L., Hamama-Raz, Y., Ben-Ezra, M., Pitcho-Prelorentzos, S., David, U. Y., Zaken, A., \& Lavenda, O. (2017). Do previous experience and geographic proximity matter? Possible predictors for diagnosing Adjustment disorder vs. PTSD. Psychiatry Research, 258, 438-443. https://doi.org/10.1016/j.psychres.2017.08.085

Muthén, B., du Toit, S. H. C., \& Spisic, D. (1997). Robust inference using weighted least squares and quadratic estimating equations in latent variable modeling with categorical and continuous outcomes. Unpublished technical report. Retrieved from https://www.statmodel.com/download/Article 075.pdf

Nickerson, A., Cloitre, M., Bryant, R. A., Schnyder, U., Morina, N., \& Schick, M. (2016). The factor structure of complex posttraumatic stress disorder in traumatized refugees. European Journal Psychotraumatology, 7, 33253.

\section{https://doi.org/10.3402/ejpt.v7.33253}

Owczarek, M., Ben-Ezra, M., Karatzias, T., Hyland, P., Vallieres, F., \& Shevlin, M. (2019). Testing the factor structure of the International Trauma Questionnaire (ITQ) in African community samples from Kenya, Ghana, and Nigeria. Journal of Loss and Trauma, 25(4), 348-363. https://doi.org/10.1080/15325024.2019.1689718

Perkonigg, A., Lorenz, L., \& Maercker, A. (2018). Prevalence and correlates of ICD-11 adjustment disorder: Findings from the Zurich Adjustment Disorder Study. 
International Journal of Clinical Health Psychology, 18(3), 209-217.

https://doi.org/10.1016/j.ijchp.2018.05.001

Raykov, T. (1997). Estimation of composite reliability for congeneric measures. Applied Psychological Measurement, 21(2). https://doi.org/10.1177/01466216970212006

Rhemtulla, M., Brosseau-Liard, P. E., \& Savalei, V. (2012). When can categorical variables be treated as continuous? A comparison of robust continuous and categorical SEM estimation methods under suboptimal conditions. Psychological Methods, 17(3), 354373. https://doi.org/10.1037/a0029315

Sankoh, O., Sevalie, S., \& Weston, M. (2018). Mental health in Africa. The Lancet Global Health, 6(9), e954-e955. https://doi.org/10.1016/s2214-109x(18)30303-6

Shevlin, M., Hyland, P., Ben-Ezra, M., Karatzias, T., Cloitre, M., Vallieres, F., Bachem, R., \& Maercker, A. (2020). Measuring ICD-11 adjustment disorder: the development and initial validation of the International Adjustment Disorder Questionnaire. Acta Psychiatrica Scandinavica, 141(3), 265-274. https://doi.org/10.1111/acps.13126

Silver, L., \& Johnson, C. (October 9, 2018). Internet use is growing across much of subSaharan Africa, but most are still offline. https://www.pewresearch.org/global/2018/10/09/internet-use-is-growing-acrossmuch-of-sub-saharan-africa-but-most-are-still-offline/

Thornicroft, G., \& Tansella, M. (2013). The balanced care model for global mental health. Psychological Medicine, 43(4), 849-863. https://doi.org/10.1017/S0033291712001420

Tol, W. A., Barbui, C., Bisson, J., Cohen, J., Hijazi, Z., Jones, L., ...\& van Ommeren, M. (2014). World Health organization guidelines for management of acute stress, PTSD, and bereavement: key challenges on the road ahead. PLoS Med, 11(12), e1001769. https://doi.org/10.1371/journal.pmed.1001769 
Tourangeau, R., \& Smith, T. W. . (1996). Asking sensitive questions: The impact of data collection mode, question format, and question context. Public Opinion Quarterly, 60, 275-304. https://doi.org/10.1086/297751

Vallieres, F., Ceannt, R., Daccache, F., Abou Daher, R., Sleiman, J., Gilmore, B., Byrne, S., Shevlin, M., Murphy, J., \& Hyland, P. (2018). ICD-11 PTSD and complex PTSD amongst Syrian refugees in Lebanon: the factor structure and the clinical utility of the International Trauma Questionnaire. Acta Psychiatrica Scandinavica, 138(6), 547557. https://doi.org/10.1111/acps.12973

World Health Organization. (2017). Mental Health Atlas. Retrived from https://apps.who.int/iris/bitstream/handle/10665/272735/9789241514019eng.pdf?ua=1

World Health Organization. (2018). International classification of diseases for mortality and morbidity statistics (11th Revision) Retrieved from https://icd.who.int/browse11/1m/en

Yuan, K.-H., \& Bentler, P. (2000). Three likelihood-based methods for mean and covariance structure analysis with non-normal missing data. Sociological Methodology, 30, 165200. https://doi.org/10.1111/0081-1750.00078

Zelviene, P., Kazlauskas, E., \& Maercker, A. (2020). Risk factors of ICD-11 adjustment disorder in the Lithuanian general population exposed to life stressors. European Journal of Psychotraumatology, 11(1), 1708617. https://doi.org/10.1080/20008198.2019.1708617 
Table 1

Demographics and prevalence of most common traumatic events and stressors.

\begin{tabular}{|c|c|c|c|}
\hline \multirow[t]{2}{*}{ Variable } & $\begin{array}{c}\text { Ghana } \\
(n=500)\end{array}$ & $\begin{array}{c}\text { Kenya } \\
(n=1006)\end{array}$ & $\begin{array}{c}\text { Nigeria } \\
(n=1018)\end{array}$ \\
\hline & \multicolumn{3}{|c|}{$n(\%)$} \\
\hline \multicolumn{4}{|l|}{ Area } \\
\hline Urban & $297(59.4)$ & $611(60.7)$ & $709(69.6)$ \\
\hline Suburban & $140(28)$ & $235(23.4)$ & $240(23.6)$ \\
\hline Rural & $63(12.6)$ & $160(15.9)$ & $69(6.8)$ \\
\hline \multicolumn{4}{|l|}{ Marital status* } \\
\hline $\begin{array}{l}\text { In a committed } \\
\text { relationship/Married }\end{array}$ & $228(45.6)$ & $553(55)$ & $565(55.5)$ \\
\hline \multicolumn{4}{|l|}{ Employment status } \\
\hline Not employed & $198(39.4)$ & $383(38.1)$ & $377(37.1)$ \\
\hline Employed & $260(54.0)$ & $567(56.4)$ & $470(56.5)$ \\
\hline Voluntary work & $42(8.4)$ & $56(5.6)$ & $66(6.5)$ \\
\hline \multicolumn{4}{|l|}{ Level of education ${ }^{* *}$} \\
\hline College/University & $442(88.4)$ & $922(91.7)$ & $956(93.9)$ \\
\hline \multicolumn{4}{|l|}{$\begin{array}{l}\text { Most common traumatic } \\
\text { events }\end{array}$} \\
\hline Natural disaster & $143(28.6)$ & $294(29.2)$ & $203(19.9)$ \\
\hline Transportation accident & $182(36.4)$ & $412(41.0)$ & $474(46.6)$ \\
\hline $\begin{array}{l}\text { Serious accident at work, } \\
\text { home, or during } \\
\text { recreational activity }\end{array}$ & $143(28.6)$ & $277(27.5)$ & $332(32.6)$ \\
\hline Physical assault & $205(41.0)$ & $553(55.0)$ & $549(53.9)$ \\
\hline $\begin{array}{l}\text { Other unwanted or } \\
\text { uncomfortable sexual } \\
\text { experience }\end{array}$ & $142(28.4)$ & $319(31.7)$ & $267(26.2)$ \\
\hline $\begin{array}{l}\text { Life-threatening illness or } \\
\text { injury }\end{array}$ & $144(28.8)$ & $286(28.4)$ & $230(22.6)$ \\
\hline \multicolumn{4}{|l|}{ Most common stressors } \\
\hline Death of a loved one & $290(58.0)$ & $619(61.5)$ & $645(63.4)$ \\
\hline Unemployment & $258(51.6)$ & $667(66.3)$ & $578(56.8)$ \\
\hline Too much /too little work & $267(53.4)$ & $669(66.5)$ & $578(56.8)$ \\
\hline $\begin{array}{l}\text { Pressure to meet } \\
\text { deadlines }\end{array}$ & $242(48.4)$ & $654(65.0)$ & $583(57.3)$ \\
\hline Financial problems & $415(83.0)$ & $892(88.7)$ & $883(86.7)$ \\
\hline Death of a loved one & $290(58.0)$ & $619(61.5)$ & $645(63.4)$ \\
\hline Unemployment & $258(51.6)$ & $667(66.3)$ & $578(56.8)$ \\
\hline
\end{tabular}

Note. ${ }^{*}$ Remainder of the participants were not in a committed relationship/Not married.

** Remainder of the participants' level of education were primary/secondary school. 
Table 2

Bivariate correlations between ADMN stressors, LEC and ADNM and ITQ Subscale scores Ghana $(n=500)$, Kenya $(n=1,006)$, and

Nigeria $(n=1,018)$

\begin{tabular}{|c|c|c|c|c|c|c|c|c|c|c|}
\hline & 1 & 2 & 3 & 4 & 5 & 6 & 7 & 8 & 9 & 10 \\
\hline \multicolumn{11}{|l|}{ Ghana and Nigeria } \\
\hline 2. LEC & .395 & 1.00 & .274 & .317 & .376 & .366 & .334 & .247 & .232 & .291 \\
\hline 4. AjD: Failure to adapt & .386 & .268 & .761 & 1.00 & .417 & .372 & .371 & .501 & .516 & .537 \\
\hline 5. PTSD: Re-experiencing & .302 & .345 & .429 & .394 & 1.00 & .573 & .527 & .407 & .337 & .329 \\
\hline 6. PTSD: Avoidance & .352 & .315 & .404 & .345 & .585 & 1.00 & .580 & .434 & .373 & .410 \\
\hline 9. DSO: Negative Self Concept & .308 & .256 & .494 & .482 & .329 & .286 & .302 & .592 & 1.00 & .658 \\
\hline 10. DSO: Disturbed Relationships & .293 & .304 & .500 & .435 & .367 & .344 & .352 & .602 & .647 & 1.00 \\
\hline \multicolumn{11}{|l|}{ Kenya } \\
\hline 1. ADNM Stressors & 1.00 & & & & & & & & & \\
\hline 2. LEC & .411 & 1.00 & & & & & & & & \\
\hline 7. PTSD: Sense of threat & .338 & .333 & .370 & .363 & .562 & .581 & 1.00 & & & \\
\hline 8. DSO: Affective dysregulation & .289 & .273 & .477 & .502 & .394 & .381 & .408 & 1.00 & & \\
\hline 9. DSO: Negative Self Concept & .263 & .255 & .485 & .515 & .364 & .363 & .314 & .590 & 1.00 & \\
\hline 10. DSO: Disturbed Relationships & .290 & .251 & .441 & .474 & .344 & .401 & .374 & .618 & .707 & 1.00 \\
\hline
\end{tabular}

Note. all correlations were $p<.001$. The correlation values for Ghana are reported in the upper half below the diagonal. The values from Nigeria are reported in the upper half in boldface. Correlation values for Kenya are reported in the bottom half and italicized. 
Table 3

Fit statistics for the alternative models of the ICD-11 adjustment disorder, PTSD and DSO symptoms Ghana $(n=500)$, Kenya $(n=$ $1,006)$, and Nigeria $(n=1,018)$

\begin{tabular}{|c|c|c|c|c|c|c|c|}
\hline Model & & Chi-square $(d f)$ & RMSEA $(90 \%$ CI $)$ & $\mathrm{CFI}$ & TLI & $\begin{array}{l}\text { SRM } \\
\mathrm{R}\end{array}$ & $\overline{B I C}$ \\
\hline \multicolumn{8}{|c|}{ 1. 1 factor model } \\
\hline \multirow{2}{*}{ Ghana } & MLR & $1608.805(152)^{*}$ & $.139(.133-.145)$ & .645 & .600 & .103 & \multirow[t]{2}{*}{26855.471} \\
\hline & WLSMV & $2575.576(152)^{*}$ & $.179(.173-.185)$ & .826 & .804 & .121 & \\
\hline \multirow{2}{*}{ Kenya } & MLR & $3068.283(152)^{*}$ & $.138(.134-.142)$ & .662 & .620 & .097 & \multirow[t]{2}{*}{55226.366} \\
\hline & WLSMV & $4678.696(152)^{*}$ & $.172(.168-.176)$ & .829 & .808 & .107 & \\
\hline \multirow{2}{*}{ Nigeria } & MLR & $2612.571(152)^{*}$ & $.126(.122-.130)$ & .703 & .666 & .087 & \multirow[t]{2}{*}{53591.406} \\
\hline & WLSMV & $2575.576(152)^{*}$ & $.179(.173-.185)$ & .826 & .804 & .121 & \\
\hline \multicolumn{8}{|c|}{ 2. 3 factor model } \\
\hline \multirow{2}{*}{ Ghana } & MLR & $599.449(167)^{*}$ & $.072(.066-.078)$ & .904 & .891 & .050 & \multirow[t]{2}{*}{26564.325} \\
\hline & WLSMV & $616.314(167)^{*}$ & $.075(.068-.080)$ & .970 & .966 & .044 & \\
\hline \multirow{2}{*}{ Kenya } & MLR & $1110.422(167)^{*}$ & $.075(.071-.079)$ & .899 & .885 & .049 & \multirow[t]{2}{*}{55043.833} \\
\hline & WLSMV & $1128.720(167)^{*}$ & $.076(.072-.0 .08)$ & .966 & .961 & .043 & \\
\hline \multirow{2}{*}{ Nigeria } & MLR & $1277.017(167)^{*}$ & $.081(.077-.085)$ & .878 & .861 & .051 & \multirow[t]{2}{*}{53995.070} \\
\hline & WLSMV & $1299.080(167)^{*}$ & $.082(.078-.086)$ & .955 & .949 & .047 & \\
\hline \multicolumn{8}{|c|}{ 3. 8 first order } \\
\hline \multirow{2}{*}{ Ghana } & MLR & $242.857(142)^{*}$ & $.038(.030-.046)$ & .978 & .970 & .029 & \multirow[t]{2}{*}{26288.681} \\
\hline & WLSMV & $297.393(142)^{*}$ & $.047(.039-.054)$ & .990 & .986 & .027 & \\
\hline \multirow{2}{*}{ Kenya } & MLR & $399.716(142)^{*}$ & $.042(.038-.047)$ & .972 & .963 & .029 & \multirow[t]{2}{*}{54390.877} \\
\hline & WLSMV & $518.367(142)^{*}$ & $.051(.047-.056)$ & .987 & .982 & .026 & \\
\hline \multirow{2}{*}{ Nigeria } & MLR & $434.701(142)^{*}$ & $.045(.040-.050)$ & .968 & .957 & .034 & \multirow[t]{2}{*}{53179.027} \\
\hline & WLSMV & $611.520(142)^{*}$ & $.057(.052-.062)$ & .981 & .975 & .029 & \\
\hline \multicolumn{8}{|c|}{ 4. 8 first order, 1 second order } \\
\hline \multirow{2}{*}{ Ghana } & MLR & $680.642(162)^{*}$ & $.080(.074-.086)$ & .885 & .865 & .081 & \multirow[t]{2}{*}{26685.533} \\
\hline & WLSMV & $610.291(162)^{*}$ & $.134(.128-.140)$ & .905 & .888 & .084 & \\
\hline \multirow{2}{*}{ Kenya } & MLR & $1195.748(162)^{*}$ & $.080(.075-.084)$ & .889 & .870 & .077 & \multirow[t]{2}{*}{55162.835} \\
\hline & WLSMV & $2787.743(162)^{*}$ & $.127(.123-.131)$ & .906 & .890 & .076 & \\
\hline
\end{tabular}




\begin{tabular}{|c|c|c|c|c|c|c|c|}
\hline Nigeria & $\begin{array}{l}\text { MLR } \\
\text { WLSMV }\end{array}$ & $\begin{array}{c}978.774(162)^{*} \\
2049.806(162)^{*}\end{array}$ & $\begin{array}{l}.070(.066-.075) \\
.107(.103-.111)\end{array}$ & $\begin{array}{l}.910 \\
.925\end{array}$ & $\begin{array}{l}.894 \\
.912\end{array}$ & $\begin{array}{l}.066 \\
.066\end{array}$ & 53675.383 \\
\hline \multicolumn{8}{|c|}{ 5. 8 first order, 3 second order } \\
\hline \multirow{2}{*}{ Ghana } & MLR & $270.259(159)^{*}$ & $.037(.030-.045)$ & .975 & .970 & .035 & \multirow[t]{2}{*}{26216.387} \\
\hline & WLSMV & $325.292(159)^{*}$ & $.046(.039-.053)$ & .989 & .987 & .032 & \\
\hline \multirow{2}{*}{ Kenya } & MLR & $479.214(159)^{*}$ & $.045(.040-.049)$ & .966 & .959 & .035 & \multirow[t]{2}{*}{54364.174} \\
\hline & WLSMV & $588.261(159)^{*}$ & $.052(.047-.056)$ & .985 & .982 & .031 & \\
\hline \multirow{2}{*}{ Nigeria } & MLR & $496.231(159)^{*}$ & $.046(.041-.050)$ & .963 & .956 & .038 & \multirow[t]{2}{*}{53132.408} \\
\hline & WLSMV & $627.389(159)^{*}$ & $.054(.049-.058)$ & .981 & .978 & .033 & \\
\hline \multicolumn{8}{|c|}{ 6. 8 first order, 3 second order with predictors } \\
\hline \multirow{2}{*}{ Ghana } & MLR & $339.559(193)^{*}$ & $.039(.032-.046)$ & .970 & .964 & .035 & \multirow[t]{2}{*}{30314.148} \\
\hline & WLSMV & 382.641 (193) & $.044(.038-.051)$ & .988 & .985 & .032 & \\
\hline \multirow{2}{*}{ Kenya } & MLR & $556.917(193)^{*}$ & $.043(.039-.048)$ & .964 & .957 & .034 & \multirow[t]{2}{*}{62273.838} \\
\hline & WLSMV & $667.270(193)^{*}$ & $.049(.045-.054)$ & .983 & .980 & .030 & \\
\hline \multirow{2}{*}{ Nigeria } & MLR & $566.200(193)^{*}$ & $.044(.039-.048)$ & .962 & .954 & .036 & \multirow[t]{2}{*}{61287.045} \\
\hline & WLSMV & $696.658(193)^{*}$ & $.051(.047-.055)$ & .980 & .976 & .032 & \\
\hline
\end{tabular}

Note. ${ }^{*} p<.001$ 


\section{Figure 1}

Factor analytic models of ICD-11 AjD, PTSD and DSO symptoms

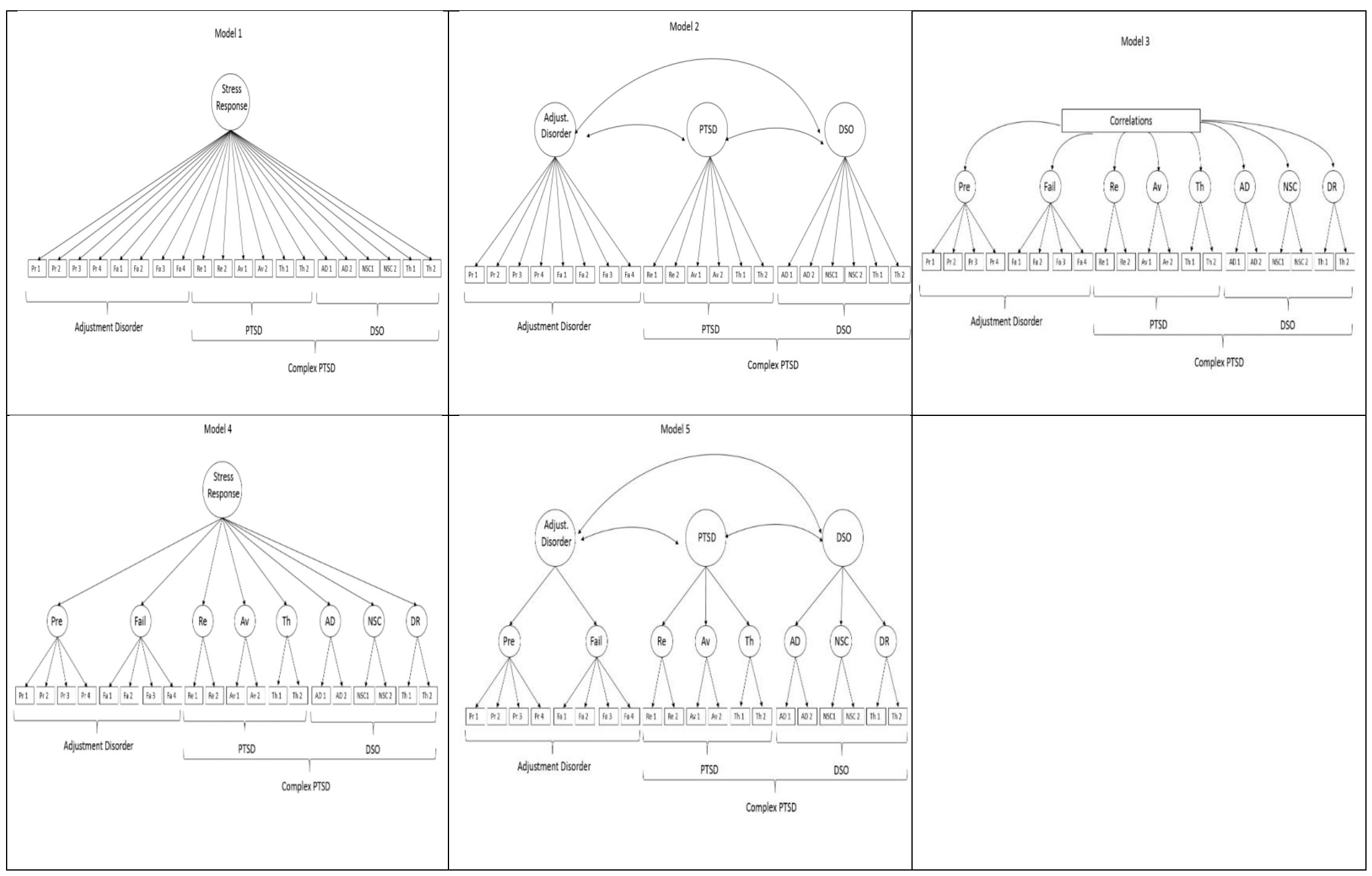


Figure 2

Estimates from factor analytic model of ICD-11 adjustment disorder, PTSD and DSO symptoms with predictors (Ghana).

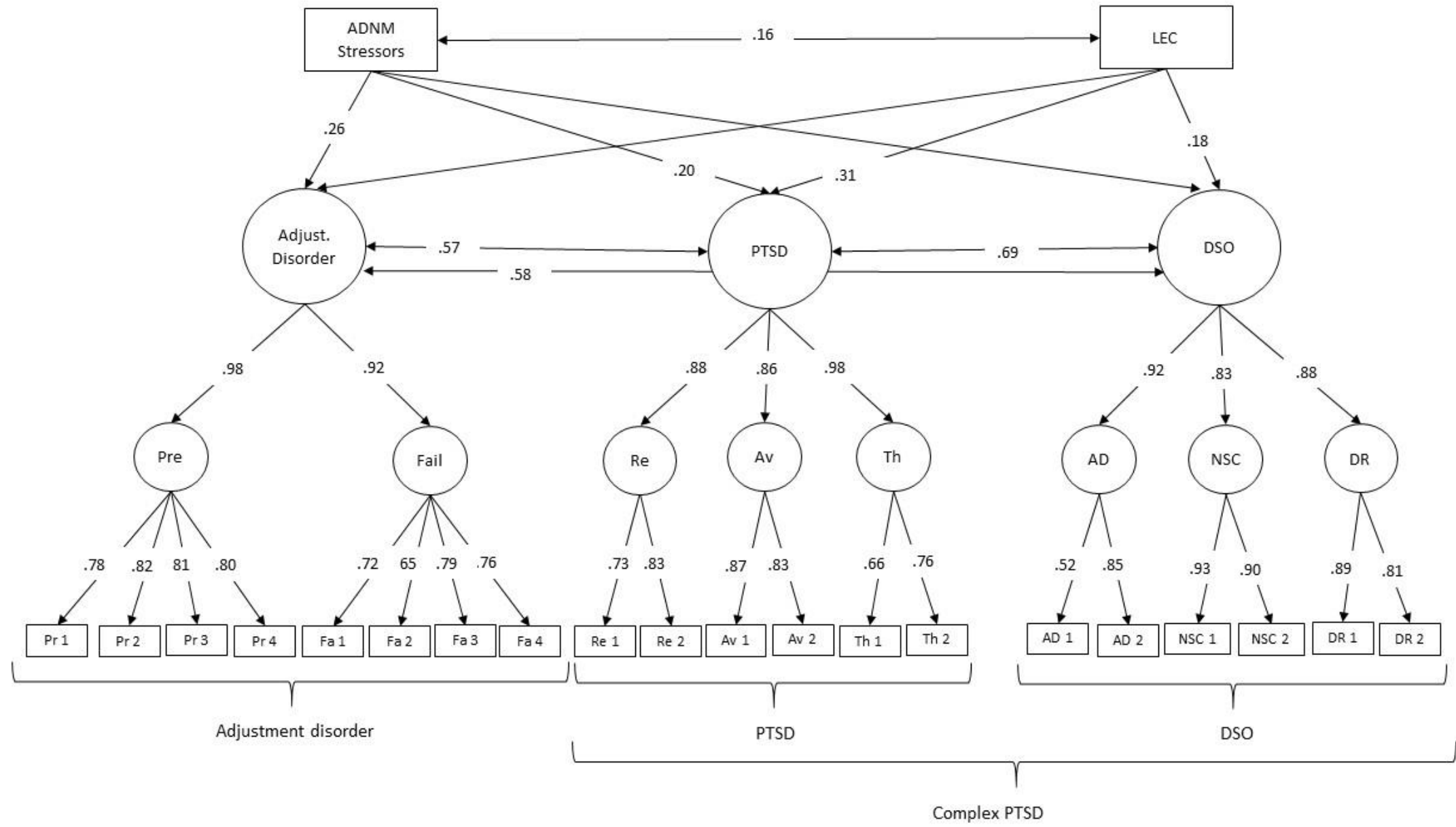

Note. only significant values $(p<.05)$ are reported. 
Figure 3

Estimates from factor analytic model of ICD-11 adjustment disorder, PTSD and DSO symptoms with predictors (Kenya).

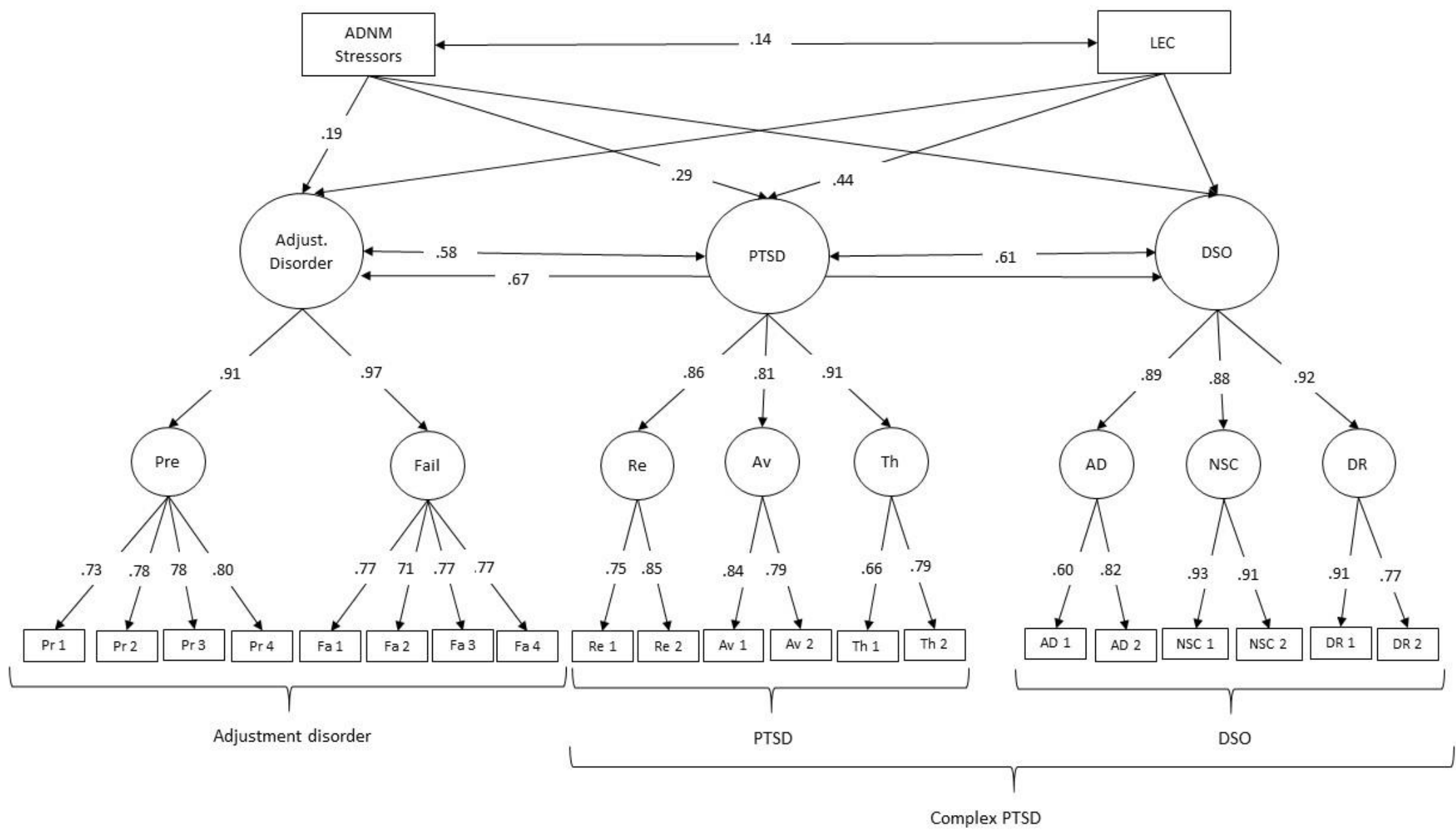

Note. only significant values $(p<.05)$ are reported. 
Figure 4

Estimates from factor analytic model of ICD-11 adjustment disorder, PTSD and DSO symptoms with predictors (Nigeria).

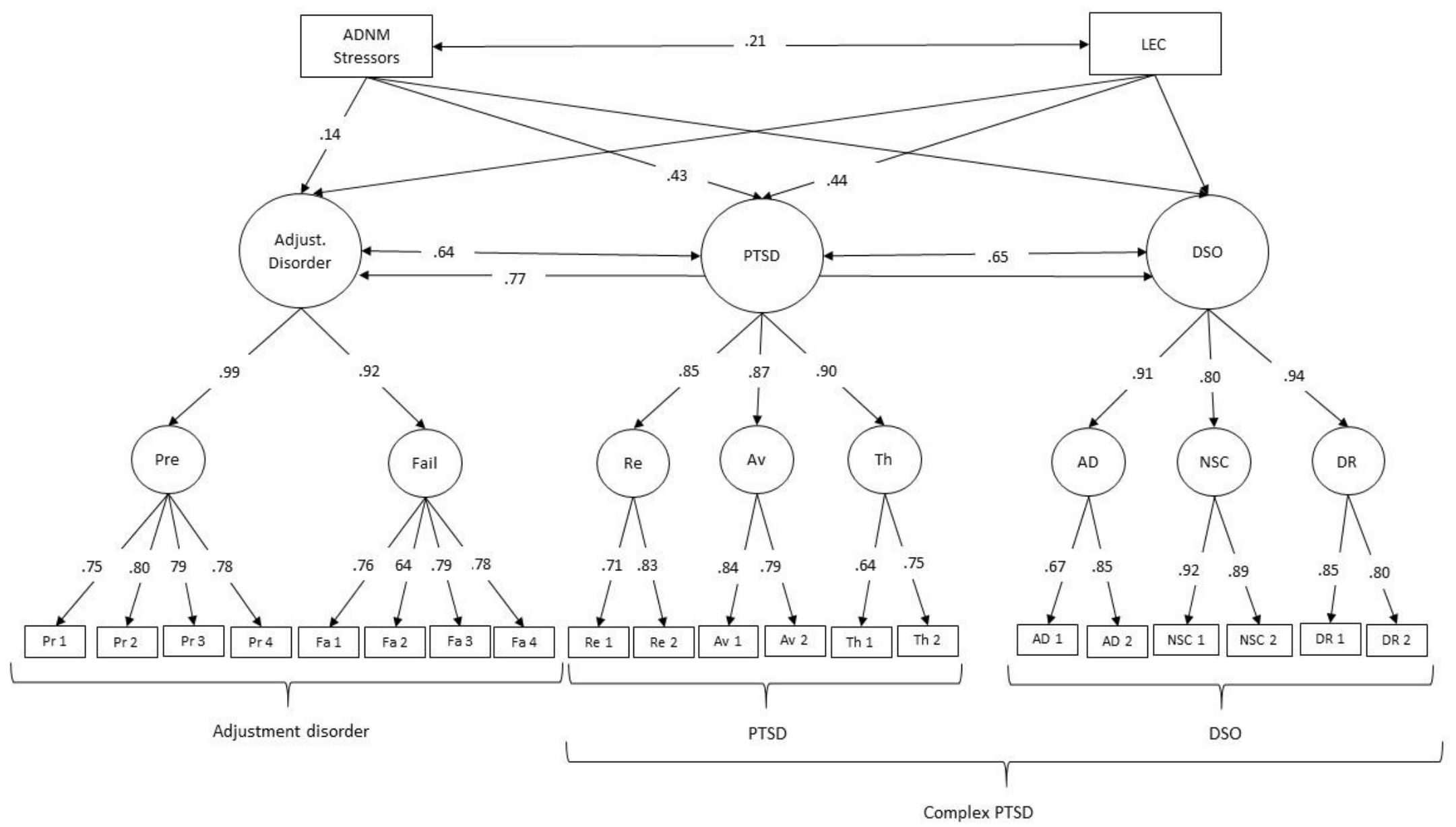

Note. only significant values $(p<.05)$ are reported. 